\title{
MODEL PEMBELAJARAN KOOPERATIF DENGAN PERMAINAN ESTAFET UNTUK MOROTIK KASAR ANAK USIA DINI
}

\author{
Rohyana Fitriani \\ Fakultas Ilmu Pendidikan, Universitas Hamzanwadi \\ Email: rohyanafitriani6@gmail.com
}

\begin{abstract}
Abstrak
Penelitian ini bertujuan untuk mengembangkan model dan mengetahui efektivitas model pembelajaran kooperatif dengan permainan estafet bagi anak usia 5-6 tahun. Penelitian dan pengembangan mengacu pada langkah yang dikembangkan Borg \& Gall. Desain pengembangan dikelompokkan menjadi 3 langkah, yaitu: (1) studi pendahuluan, (2) proses pengembangan, (3) uji coba dan finalisasi. Subjek uji coba lapangan awal adalah 20 anak kelompok B TK ABA Karangmalang Yogyakarta. Subjek uji coba lapangan luas adalah 32 anak dari dua sekolah yaitu TK ABA Karangmalang dan TK Nasional Samirono. Subjek uji operasional berjumlah 33 anak TK Al-Falaah Batu Belek. Pengumpulan data menggunakan pedoman wawancara, lembar angket, dan lembar observasi. Teknik analisis data menggunakan Percentage of Agreement dan Paired Samples Test dengan taraf signifikansi 0,05. Hasil antara pretest dan postest setelah menggunakan pembelajaran kooperatif dengan permainan estafet dengan $\mathrm{p}<0,05$ yaitu nilai signifikansi sebesar 0,000. Hasil tersebut menunjukkan bahwa model pembelajaran kooperatif dapat meningkatkan keterampilan motorik kasar anak.
\end{abstract}

Kata Kunci: model kooperatif, estafet, motorik kasar.

\begin{abstract}
This research discusses: developing models and studying cooperative learning models with relay games for children aged 5-6 years. Research and development were developed at the step developed by Borg \& Gall. The development design is grouped into 3 steps, namely: (1) a preliminary study, (2) the development process, (3) trials and finalization. The subjects of the initial field trial were 20 children from group $B T K A B A$ Karangmalang, Yogyakarta. The subjects of the large field trial were 32 children from two schools, namely TK ABA Karangmalang and TK Samirono National. Operational test subjects approved 33 children from Al-Falaah Batu Belek Kindergarten. Data collection uses interview sheets, questionnaire sheets, and observation sheets. Data analysis techniques used were Agreement Percentage and Paired Samples Test with a significance level of 0.05 . The results between the pretest and posttest after using cooperative learning with relay games with $p<0.05$ is a significance value of 0,000. These results indicate that the cooperative learning model can improve children's gross motor skills.
\end{abstract}

Keywords: cooperative model, relay, gross motor. 



\section{PENDAHULUAN}

Undang-Undang No. 20 tahun 2003 Pasal 1 butir 14 menyebutkan bahwa pendidikan anak usia dini merupakan suatu upaya pembinaan yang ditujukan kepada anak sejak lahir sampai dengan usia enam tahun yang dilakukan melalui pemberian rangsangan pendidikan untuk membantu pertumbuhan dan perkembangan jasmani dan ruhani agar anak memiliki kesiapan dalam memasuki pendidikan lebih lanjut. (Muhammad Fadlillah, 2014:67)

Pendidikan anak usia dini sangat penting diberikan, karena itu anak sejak dini harus diberikan stimulasi untuk mendukung perkembangan daya pikirnya. Bermain merupakan salah satu cara yang tepat untuk memberikan stimulasi pada anak usia dini. Bermain merupakan wadah untuk berimajinasi dan mengeluarkan semua ide-ide yang ada dalam diri anak. Pentingnya pemberian stimulasi pada anak melalui bermain, artinya titik tekannya adalah anak dalam proses pembelajaran merasa senang.

Bermain merupakan sarana yang digunakan dalam menggali pengalaman belajar yang bermanfaat untuk anak, seperti anak dihadapkan dalam permainan role playing (bermain peran), anak akan belajar melalui permainan tersebut untuk berkomunikasi, membina hubungan bersama teman, dan melatih anak berbicara dengan perbendaharaan kata yang secara tidak disadari oleh anak akan bertambah. Contoh lainnya, anak bermain dengan aktivitas fisik yang membutuhkan banyak energi atau disebut dengan permainan aktif,anak berjalan, berlari, melempar bola, melompat, dan sebagainya akan melatih anggota tubuh anak bergerak, dan hal tersebut sebagai salah satu permainan yang melatih perkembangan motorik kasar anak. Sesuai dengan apa yang dinyatakan oleh Heri Rahyubi (2012:228) perkembangan motorik khususnya pada anak usia dini akan lebih optimal jika lingkungan tempat tumbuh kembang anak mendukung anak untuk bergerak bebas. Kegiatan di luar ruangan bisa menjadi pilihan terbaik karena dapat menstimulasi perkembangan otot. Jika anak melakukan aktivitas di dalam ruangan, maka pemaksimalan ruangan bisa dijadikan strategi untuk menyediakan ruang gerak yang bebas bagi anak untuk berlari, melompat, 
dan menggerakkan seluruh tubuhnya dengan cara-cara yang tidak terbatas.

Berdasarkan observasi awal di sekolah penulis menemukan permasalahan-permasalahan, di antaranya adalah dalam proses pembelajaran ditemukan ketidakseimbangan stimulasi yang diberikan antara motorik kasar dan motorik halus. Hal ini menjadi masalah penting yang perlu dibahas, berdasarkan apa yang dituturkan oleh salah satu guru/pendidik di TK AlFalaah mengungkapkan bahwa pada proses pembelajaran stimulasi yang diberikan lebih banyak menekankan pada perkembangan motorik halus anak seperti menggunting, mewarnai gambar, bermain balok, dan sebgainya. Pengembangan motorik kasar anak pada kelompok B masih rendah, hal ini diketahui pada tingkat motivasi anak yang rendah dalam melakukan kegiatan-kegiatan dalam upaya mengembangkan motorik kasar. Kurangnya stimulasi pengembangan motorik kasar disebabkan pula oleh kurangnya alat peraga atau media di sekolah. Agar kegiatan pengembangan motorik kasar anak dapat terlaksana dengan baik, anak dituntut untuk memiliki perhatian dan daya tahan yang baik seperti disiplin, kerjasama, kecepatan anak dalam bereaksi, memiliki konsentrasi yang cukup dalam pengembangan motorik kasar.

Menggunakan model pembelajaran yang tepat dengan pemilihan media yang sesuai dengan aspek perkembangan yang ingin dicapai tetap mengedepankan unsur bermain dapat dijadikan sebagai wadah pengembangan motorik kasar anak seperti model pembelajaran yang dikembangkan oleh peneliti yakni model pembelajaran kooperatif dengan permainan estafet. Hal yang dapat dikatakan ada dalam unsur bermain adalah gerakan-gerakan tubuh atau aktifitas aktif anak.

Luo \& Sun (2013:42-43) menjelaskan bahwa pada pembelajaran keterampilan motorik, hanya sedikit yang menunjukkan bahwa pembelajaran kelompok atau kooperatif bisa meningkatkan kemampuan motorik, akan tetapi dalam studi Barret (2005) bahwa terdapat tiga elemen pembelajaran kooperatif yang dapat menunjang keberhasilan keterampilan motorik. Ketiga elemen pembelajaran kooperatif tersebut adalah interaksi kooperatif, akuntabilitas individu, dan ketergantungan positif. 
Pengembangan keterampilan motorik dengan menggunakan pembelajaran kooperatif dapat dijadikan sebagai penghubung dengan kognitif yang diantaranya sistem kerja memori dan perhatian. Pembelajaran kooperatif dengan keterampilan motorik memiliki keterhubungan yang ditekankan pada kegiatan bermain seperti permainan dengan alat bantu.

Menurut Dikdik (2010:8) permainan estafet adalah permainan yang terdiri atas kelompok, setiap kelompok berlari kecil (jog) berbanjar melingkari dua buah tanda. Pelari pertama tiap kelompok membawa sebuah tongkat, pada suatu tanda yang disepakati pelari pertama menjauhi teman lain mengikuti jalur lintasan sampai mencapai pelari terakhir dari kelompok. Tongkat atau benda yang diberikan kepada pelari baru yang akan membawa tongkat tersebut, dan begitu seterusnya.

Desain permainan estafet yang akan dikembangkan oleh penulis adalah permainan estafet yang dimodifikasi. Lutan (1997:9) menyatakan bahwa modifikasi diartikan sebagai perubahan dari keadaan lama menjadi keadaan baru. Perubahan itu dapat berupa bentuk, fungsi, cara penggunaan, dan manfaat tanpa sepenuhnya menghilangkan karakteristik semula. Permainan yang dimodifikasi dapat dimaknai dengan perubahan dalam permainan dari teknik bermain baku menjadi teknik yang sederhana sesuai dengan perkembangan anak.

Permainan estafet yang dikembangkan dan akan diterapkan kepada anak bukan estafet tongkat, tetapi estafet menyelesaikan gerakangerakan permainan di perrsebaran tujuh pos dengan tanda estefet adalah menepuk bahu anak yang lain dan melanjutkan menyelesaikan permainan. Hal ini didasarkan pada kemampuan anak melakukan permainan lari estafet yang sesungguhnya belum bisa dilaksanakan, sehingga perlu dimodifikasi agar anak dapat bermain sesuai dengan perkembangan kemampuan anak.

Lestari \& Ratna Ningsih (2016:217-218) menjelaskan bahwa masa prasekolah adalah masa bermain, sehingga permainan yang dimodifikasi untuk anak prasekolah merupakan alternatif dalam keterampilan anak. Permainan yang dimodifikasi menekankan tentang kemampuan anak secara berkelompok. Permainan dengan 
pendekatan berkelompok akan menarik minat anak-anak untuk berpartisipasi dalam proses pembelajaran. Dilihat dari aspek perkembangan motorik, permainan yang menekankan tentang kegiatan berkelompok dapat membuat anak merasa senang. Permainan dengan penedekatan kooperatif terdapat beberapa aspek yaitu koordianasi mata dan tangan atau mata dan kaki, gerakan lokomotor, gerakan non lokomotor dan pengelolaan serta pengendalian tubuh.

$$
\text { Hasil pengamatan yang }
$$
dilakukan oleh Dwi Septi (2015) 70$80 \%$ anak usia dini melakukan gerak pada proses belajarnya. Anak usia dini menghabiskan banyak waktunya dengan aktifitas bergerak, saat anak berinteraksi dengan lingkungan sosialnya anak membutuhkan kemampuan gerak dasar yang baik agar dapat mengimbangi gerak teman sebayanya seperti berjalan, berlari, melompat dan kegiatan bermain lainnya. Jika kematangan perkembangan motorik kasar anak terhambat tidak menutup kemungkinan kegiatan interaksi anak dengan lingkungan sosialnya juga dapat terhambat.
Berdasarkan hasil penelitian yang dilakukan oleh Nisnayeni (2012) menjelaskan bahwa perkembangan motorik terutama motorik kasar anak merupakan kebutuhan pokok yang menjadikan pertumbuhan dan kematangan anak dalam mengembangkan suatu keterampilan. Hal ini dikarenakan, setiap periode usia anak akan menjadikan keterampilan anak bertambah. Kualitas motorik anak terlihat dari seberapa jauh anak mampu menampilkan tugas motorik dengan tingkat keberhasilan tertentu. Keberhasilan motorik anak tidak hanya didukung melalui pemenuhan status gizi saja, akan tetapi stimulasi yang diberikan, sehingga dengan stimulasi yang optimal perkembangan motorik anak akan sesuai dengan tahap perkembangan yang diinginkan.

\section{METODE PENELITIAN}

\section{Model Pengembangan}

Model yang digunakan dalam penelitian ini adalah model penelitian dan pengembangan Research and Development (R\&D). Model pengembangan yang digunakan dalam penelitian ini mengacu pada model Borg \& Gall. Model pengembangan Borg and Gall ini dalam prosesnya terdiri atas 10 (sepuluh) langkah atau 
10 tahapan yaitu: (1) Research and information collection, (2) Planning, (3) Develop preliminary form of product, (4) Preliminary Field Testing, (5) Main product revision, (6) Main field testing, (7) Operational product revision, (8) Operational field testing, (9) Final product revision, (10) Dissemintaion and Implementation (Borg \& Gall (1983:772). Pada penelitian ini, peneliti meniadakan langkah ke 10 dissemination and implementation (diseminasi dan implementasi).

\section{Waktu dan Tempat Penelitian}

Waktu pelaksanaan penelitian dan pengembangan yaitu bulan Januari-April 2017. Tempat penelitian uji terbatas TK ABA Karangmalang, uji lapangan melibatkan TK ABA Karangmalang dan TK Nasional Samirono Yogyakarta, dan uji operasional dilaksanakan di TK AlFalaah Batu Belek Kecamatan Rakam.

\section{Subjek Penelitian}

Subjek penelitian terdiri dari 85 anak usia 5-6 tahun yakni pada uji terbatas melibatkan subjek penelitian berjumlah 20 anak TK ABA Karangmalang Yogyakarta, uji lapangan melibatkan subjek 32 anak (19 TK ABA Karangmalang dan 13
TK Nasional Samirono Yogyakarta), dan uji opersional melibatkan 33 anak kelompok B TK Al-Falaah Batu Belek Kecamatan Rakam.

\section{Prosedur}

Berdasarkan skema penelitian dan pengembangan Borg \& Gall yang berlangsung dalam 10 (sepuluh) langkah. Secara garis besar langkah penelitian dan pengembangan terdiri atas tiga tahap, yaitu:

1) Studi Pendahuluan, studi pendahuluan merupakan tahap awal atau persiapan untuk pengembangan, dilakukan pengumpulan informasi mengenai proses kegiatan pembelajaran di PAUD. Temuan di lapangan selanjutnya dikaji untuk mempelajari konsepkonsep atau teori-teori yang berkenaan dengan produk berupa model pembelajaran dengan permainan estafet yang akan dikembangkan.

2) Pengembangan Produk, tahap ini dirumuskan arah pengembangan model pembelajaran berdasarkan kajian yang ditemukan di lapangan pada tahap sebelumnya. Langkah-langkah dalam tahap ini meliputi penyesuaian konsep, struktur produk berupa model 
pembelajaran dengan permainan estafet.

3) Uji coba produk dan finalisasi, setelah melalui tahap pengembangan, produk yang dikembangkan yang telah divalidasi oleh tim ahli, selanjutnya akan diterapkan di lapangan. Uji coba terbatas dan uji coba lapangan merupakan cara yang dilakukan untuk mengetahui tingkat kelayakan produk yang telah dikembangkan. Setelah melewati dua tahap uji coba, dilakukan uji operasional untuk mengetahui efektivitas dari penggunaan produk yang dikembangkan. Hasil dari uji operasional menjadi landasan untuk melakukan revisi tahap akhir terhadap produk yang dikembangkan dan akan menghasilkan produk final. Pada uji efektivitas dilakukan penelitian pre-experimentaldesign dengan desain one-group pretest-posttest design.

\section{Data, Intrumen, dan Teknik Pengumpulan Data \\ Data yang dikumpulkan berupa data kualitatif dan data kuantitatif melalui lembar validasi, lembar}

angket, lembar observasi, dan pedoman wawancara

a) Validasi

Lembar validasi digunakan untuk menguji kelayakan produk yang dikembangkan. Proses validasi produk yang dilakukan oleh para ahli menjadi acuan untuk mengetahui sejauh mana produk yang dikembangkan sudah memiliki kriteria yang sesuai. Hasil validasi yang dilakukan oleh validator adalah berdasarkan analisis deskriptif apakah produk yang dikembangkan sudah layak digunakan dalam proses pembelajaran baik dilihat dari segi materi dan tampilan produk.

Tabel 1. Kisi-kisi validasi ahli materi

\begin{tabular}{llc}
\hline No. & \multicolumn{1}{c}{ Indikator } & $\begin{array}{c}\text { Jumlah } \\
\text { Item }\end{array}$ \\
\hline 1 & $\begin{array}{l}\text { Tujuan } \\
\text { pembelajaran }\end{array}$ & 3 \\
\hline 2 & $\begin{array}{l}\text { Langkah-langkah } \\
\text { pembelajaran } \\
\text { (sintaks) }\end{array}$ & 3 \\
\hline 3 & $\begin{array}{l}\text { Pengembangan } \\
\text { aspek motorik } \\
\text { kasar }\end{array}$ & 18 \\
\hline
\end{tabular}

Tabel 2. Kisi-kisi validasi ahli media

\begin{tabular}{llc}
\hline No. & \multicolumn{1}{c}{ Indikator } & $\begin{array}{c}\text { Jumlah } \\
\text { Item }\end{array}$ \\
\hline 1 & Kejelasan media & 5 \\
\hline 2 & Tujuan & 3 \\
\hline 3 & $\begin{array}{l}\text { Kemenarikan } \\
\text { media }\end{array}$ & 15 \\
\hline 4 & Kesesuaian & 5 \\
\hline 5 & Kemenarikan buku & 4 \\
\hline
\end{tabular}




\begin{tabular}{lll}
\hline & panduan & \\
\hline 6 & $\begin{array}{l}\text { Kejelasan buku } \\
\text { panduan }\end{array}$ & 2 \\
\hline
\end{tabular}

b) Angket

Pada penelitian pengembangan ini, angket digunakan untuk mencari informasi yang lengkap mengenai keefektifan dari produk yang dikembangkan terhadap proses pembelajaran. Angket juga digunakan untuk mengetahui respon anak terhadap produk yang dikembangkan.

Tabel 3. Kisi-kisi angket respon anak

\begin{tabular}{lc}
\hline \multicolumn{1}{c}{ Aspek yang direspon } & $\begin{array}{c}\text { Jumlah } \\
\text { item }\end{array}$ \\
\hline $\begin{array}{l}\text { Muatan permainan } \\
\text { estafet dapat menarik } \\
\text { minat anak }\end{array}$ & 1 \\
\hline $\begin{array}{l}\text { Muatan permainan } \\
\text { estafet dapat } \\
\text { meningkatkan kegiatan } \\
\text { fisik anak }\end{array}$ & 1 \\
\hline $\begin{array}{l}\text { Langkah-langkah } \\
\text { pembelajaran mudah } \\
\text { dipahami oleh anak }\end{array}$ & 1 \\
\hline $\begin{array}{l}\text { Langkah-langkah } \\
\text { pembelajaran dapat } \\
\text { dilakukan dengan baik }\end{array}$ & 1 \\
\hline $\begin{array}{l}\text { Semua gerakandi } \\
\text { and }\end{array}$ & \\
\hline
\end{tabular}

Semua gerakan di masing-masing pos dapat 1 dilakukan oleh anak

Alat permainan sesuai dengan kemampuan fisik 1 anak c) Observasi

Dalam penelitian pengembangan ini observasi dilakukan untuk mengetahui tingkat keberhasilan produk yang dikembangkan berupa model pembelajaran kooperatif dengan permainan estafet saat digunakan dalam proses pembelajaran. Observasi dilakukan oleh observer (teman sejawat).

Tabel 4. Kisi-kisi lembar observasi

\begin{tabular}{lc}
\hline \multicolumn{1}{c}{ Indikator } & $\begin{array}{c}\text { Jumlah } \\
\text { Item }\end{array}$ \\
\hline $\begin{array}{l}\text { Kemampuan tubuh } \\
\text { melakukan gerakan-gerakan } \\
\text { ke bentuk yang lebih khusus }\end{array}$ & 2 \\
\hline $\begin{array}{l}\text { Memiliki tumpuan dan } \\
\text { tolakan yang kuat }\end{array}$ & 2 \\
\hline $\begin{array}{l}\text { Kemampuan tubuh } \\
\text { menopang gerakan atas } \\
\text { dalam suatu periode }\end{array}$ & 1 \\
\hline $\begin{array}{l}\text { Kemampuan } \\
\text { mempertahankan posisi } \\
\text { tubuh tetap seimbang }\end{array}$ & 2 \\
\hline $\begin{array}{l}\text { Kemampuan tubuh } \\
\text { mengubah arah dan posisi } \\
\text { tubuh dengan cepat dan } \\
\text { tepat }\end{array}$ & 2 \\
\hline
\end{tabular}

d) Wawancara tidak terstruktur

Wawancara tidak terstruktur dilakukan untuk mengetahui keterlaksanaan dan kebermaknaan produk yang dikembangkan, 
pengaruh produk yang dikembangkan terhadap proses pembelajaran berdasarkan keterangan dari guru.

\section{Teknik Analisis Data}

Langkah-langkah analisis data sebagai berikut:

1) Analisis hasil validasi

a) Tabulasi semua data yang diperoleh dari validator untuk setiap komponen dan butir penilaian yang tersedia dalam instrumen.

b) Hitung skor total setiap komponen.

c) Mengubah skor total menjadi nilai dengan kriteria skala lima dengan kategori pilihan tanggapan yaitu sangat baik (5), baik (4), cukup baik (3), kurang baik (2), tidak baik (1). Skor yang diperoleh melalui data yang berupa masukan dari tim ahli dianalisis secara deskriptif kuantitatif, kemudian data yang didapatkan diolah menggunakan rumus skala likert (Eko. P.W., 2009:238).

2) Analisis hasil angket

Mengubah skor total menggunakan kriteria agreement, untuk penilaian skor total dengan model instrumen penilaian "ya" dan "tidak" konversi kualitatif menggunakan rumus precentage of agreement.

$\%$ agreements =

$\frac{\text { agree }}{\text { disagree +agree }} \times 100$

3) Analisis hasil observasi

Pada uji efektivitas dilakukan penelitian pre-experimental-design dengan desain one-group pretestposttest design, dengan uji prasyarat yaitu:

a. Uji normalitas yang bertujuan untuk mengetahui distribusi data yang digunakan dalam penelitian adalah data yang memiliki distribusi normal. Uji normalitas dilakukan terhadap data hasil pretest dan post-test. Uji normalitas dilakukan dengan menggunakan program SPSS (Statistical Product and Services Solutions) 23 for Windows dengan Shapiro-Wilk.

b. Uji t - Paired Samples Test, analisis ini digunakan untuk mengetahui perbedaan rata-rata antara nilai pre-test dan nilai posttest kelompok eksperimen

\section{HASIL PENELITIAN DAN PEMBAHASAN}

Tabel 5. Hasil Validasi

\begin{tabular}{lll|l|l|l}
\hline \multicolumn{2}{l|}{ Validasi } & 1 & $\mathrm{~K}$ & 2 & $\mathrm{~K}$ \\
\hline M Dr. Harun & 92 & B & 115 & SB
\end{tabular}

A Rasyid 


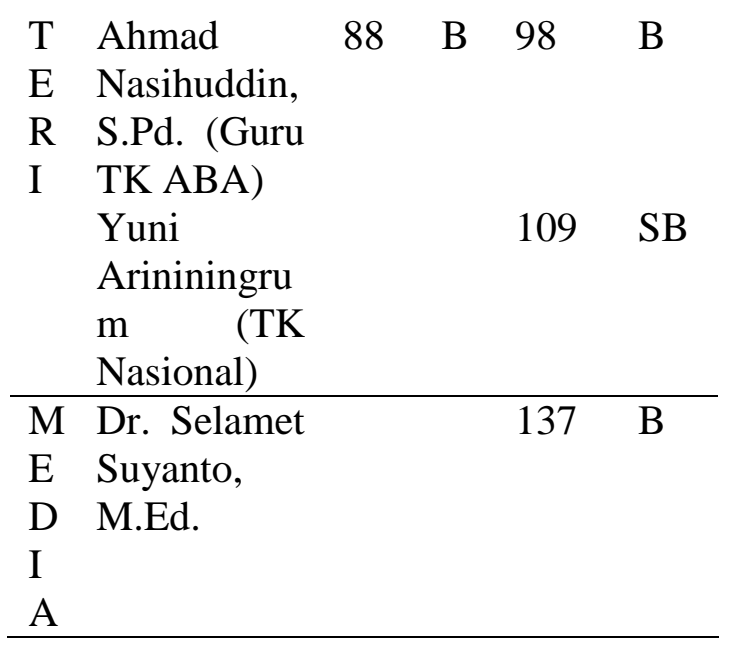

Keterangan:

$1=$ skor uji terbatas

$2=$ skor uji lapangan (luas)

$\mathrm{K}=$ kriteria

$\mathrm{B}=$ Baik

$\mathrm{SB}=$ Sanga baik

Hasil validasi media pada uji terbatas, validator memberikan masukan secara deskriptif yakni dalam produk yang dikembangkan indikator agility (kelincahan) belum ada, sehingga gerakan dalam permainan estafet dapat ditambah untuk menstimulasi gerak lincah anak yaitu ditambah gerakan zigzag dalam permainan estafet yang dikembangkan. Berdasarkan hasil validasi yang dilakukan oleh validator dan beberapa orang guru, produk yang dikembangkan layak digunakan dalam pembelajaran fisik anak usia dini.

Tabel 6. Angket respon anak terhadap model pembelajaran kooperatif dengan permainan estafet (ujicoba skala besar)

\begin{tabular}{|c|c|c|c|}
\hline \multirow{2}{*}{$\begin{array}{l}\mathbf{N} \\
\mathbf{o}\end{array}$} & \multirow{2}{*}{$\begin{array}{c}\text { Aspek yang } \\
\text { direspon }\end{array}$} & \multicolumn{2}{|c|}{ Respon anak } \\
\hline & & Ya & Tidak \\
\hline 1 & $\begin{array}{l}\text { Menarik minat } \\
\text { anak }\end{array}$ & $100 \%$ & $0 \%$ \\
\hline 2 & $\begin{array}{l}\text { Meningkatkan } \\
\text { kegiatan fisik }\end{array}$ & $100 \%$ & $0 \%$ \\
\hline 3 & $\begin{array}{l}\text { Pembelajaran } \\
\text { mudah } \\
\text { dipahami }\end{array}$ & $100 \%$ & $0 \%$ \\
\hline 4 & $\begin{array}{l}\text { Pembelajaran } \\
\text { dapat } \\
\text { dilakukan } \\
\text { dengan baik }\end{array}$ & $100 \%$ & $0 \%$ \\
\hline 5 & \begin{tabular}{lr}
\multicolumn{2}{l}{ Semua } \\
setiap perakan \\
dapat \\
dilakukan \\
anak
\end{tabular} & $87,5 \%$ & $12,5 \%$ \\
\hline 6 & $\begin{array}{l}\text { Alat } \\
\text { permainan } \\
\text { sesuai dengan } \\
\text { kemampuan } \\
\text { fisik anak }\end{array}$ & $100 \%$ & $0 \%$ \\
\hline & $\begin{array}{c}\text { Jumlah } \\
\text { persentase }\end{array}$ & $\begin{array}{l}587,5 \\
\%\end{array}$ & $12,5 \%$ \\
\hline & $\begin{array}{l}\text { Rata-rata } \\
\text { persentase }\end{array}$ & $\begin{array}{l}97,91 \\
\%\end{array}$ & $2,083 \%$ \\
\hline
\end{tabular}

Selain penilaian yang dilakukan oleh validator, peneliti juga menggunakan angket respon anak untuk mengetahui sejauh mana respon positif yang diberikan anak dan untuk mengetahui sejauh mana tingkat kebermaknaan, kemenarikan, dan pemahaman anak terhadap produk hasil pengembangan yaitu model pembelajaran dengan estafet. Pada ujicoba skala besar respon positif 
anak terhadap produk hasil pengembangan memperoleh $97,91 \%$. Respon positif anak meningkat dari ujicoba terbatas (skala kecil) 6,25\% yaitu 91,66\%. Berdasarkan data angket respon anak pada ujicoba skala besar yang terdiri dari 32 responden dapat disimpulkan bahwa produk hasil pengembangan sudah layak digunakan untuk anak.

Tabel. 7 Hasil Pre-test dan Post-test Motorik Kasar Anak Usia Dini pada Uji Operasional di TK Al-Falaah.

\begin{tabular}{lll}
\hline & Pre-tes & Post-test \\
\hline Rata-rata & 23,36 & 31,27 \\
\hline Presentase & $64,89 \%$ & $86,86 \%$ \\
\hline
\end{tabular}

Uji operasional dilaksanakan selama 8 kali pertemuan dalam waktu satu bulan dengan 2 kali pertemuan dalam 1 minggu yaitu tanggal 15 Maret, 18 Maret, 22 Maret, 25 Maret, 29 Maret, 1 April, 5 April, 8 April. Selama 8 kali pertemuan guru melakukan proses pembelajaran kurang lebih 2 jam pelajaran dengan sebelumnya mempelajari video dan buku panduan pembelajaran kooperatif dengan estafet. Sebelum dilakukan penelitian, sehari sebelumnya dilakukan pre test terhadap anak dan observer memberikan penilaian terhadap lembar observasi yang telah disediakan, pre test bertujuan untuk mengetahui tingkat kemampuan awal anak.

Setelah dilakukan pre test kepada anak, guru memberikan perlakuan yaitu penerapan model kooperatif dengan permainan estafet dalam pembelajaran selama 8 kali pertemuan. Guru dan anak dapat melaksanakan seluruh kegiatan pembelajaran kooperatif dengan estafet dengan baik. Pada akhir kegiatan pembelajaran yaitu setelah pemberian perlakuan selama 8 kali pertemuan selesai, peneliti memberikan post test yang dinilai oleh observer. Pemberian post test bertujuan untuk mengetahui efektifitas penggunaan produk hasil pengembangan dalam proses pembelajaran.

Berdasarkan hasil pre test dan post test peneliti kemudian melakukan analisis statistik. Peneliti melakukan uji prasyarat berupa uji normalitas homogenitas selanjutnya menggunakan analisis Independent Samples Test.

Tabel 8. Uji Normalitas pre-test dan post-test.

\begin{tabular}{llll}
\hline & \multicolumn{3}{c}{ Shapiro-Wilk } \\
& statistic & df & Sig. \\
\hline Pretest &, 957 & 33 &, 213 \\
\hline Postest &, 954 & 33 &, 179 \\
\hline
\end{tabular}


Berdasarkan tabel, nilai signifikansi lebih besar dari 0,05 untuk pretest dan postest, sehingga dapat disimpulkan data berdistribusi normal.

Tabel 9. Paired Sample Test

\begin{tabular}{lllll}
\hline & & T & Df & $\begin{array}{l}\text { Sig } \\
(2- \\
\text { taile } \\
\text { d) }\end{array}$ \\
\hline Pair 1 & $\begin{array}{l}\text { Pretest } \\
\text { Postest }\end{array}$ & $-22,479$ & 32 &, 000 \\
\hline
\end{tabular}

Pada output Paired Samples

Test terlihat bahwa nilai sig (2-tailed) kurang dari 0,05 yaitu 0,000. Jadi dapat disimpulkan bahwa Ho ditolak dan Ha diterima atau hasil posttest lebih baik dibandingkan dengan hasil pretest pada taraf signifikansi $<0,05$. Terdapat perbedaan yang signifikan antara hasil pretest dan postest.

\section{SIMPULAN}

Penggunaan model pembelajaran kooperatif dengan permainan estafet secara keseluruhan telah mengalami peningkatan pada nilai post test anak dari kemampuan awal anak atau pre test dan dengan percentage agreement $97,91 \%$. Pada ouput Paired Sample $t$ Test terlihat bahwa nilai sig (2-tailed) yaitu 0,000 kurang dari 0,05. Jadi dapat disimpulkan bahwa Ho ditolak dan Ha diterima. Terdapat perbedaan yang signifikan antara hasil pre test dan post test atau terdapat perbedaan antara sebelum dan sesudah diberikan perlakuan, sehingga penggunaan model pembelajaran dengan estafet dapat dikatakan efektif untuk pembelajaran motorik pada anak usia dini.

\section{DAFTAR PUSTAKA}

Borg, W. R. \& Gall, M. D. (1983). Educational Research. New York \& London: Longman.

Dikdik Z.S. (2010). Mengajar dan Melatih Atletik. Bandung: PT Remaja Rosdakarya.

Eko Putro Widoyoko. (2009). Evaluasi Program Pembelajaran Panduan Praktis Bagi Pendidik dan Calon Pendidik. Yogyakarta: Pustaka Belajar.

Muhammad Fadlillah. (2014). Desain Pembelajaran PAUD. Yogyakarta: Ar-Ruzz Media.

Lestari, Indah \& Ratnaningsih. (2016). The Effects of Modified Games on the Development of Gross Motor Skill in Preschoolers. International Journalh of Evaluation and Research in Education (IJERE). Vol. 5. No. 3, pp. 216-220.

Luo, Yi \& Sun, Yun. (2013). The Effects of Collectivism-Individualism on the Cooperative Learning of Motor Skill. Journal of International Students, Vol. 3.

Lutan, R. (1997). Belajar Keterampilan Motorik. Jakarta: Dikbud.

Nisnayeni. (2012). Peningkatan Perkembangan Motorik Kasar Anak Melalui Senam Irama di 
Taman Kanak-Kanak Bina Ummat Pesisir Selatan. Volume 1. No. 1.

Heri Rahyubi. (2012). Teori-Teori Belajar dan Aplikasi Pembelajaran Motorik. Bandung: Nusa Media.

Septi, Dwi. (2015). Peningkatan Kemampuan Gerak Lokomotor Melalui Permainan Lari Estafet Modifikasi. Jurnal PAUD UNJ. Edisi 9 Volume 1. 